\title{
A 10-year follow-up of adiposity and dementia in Swedish adults aged 70-years and older
}

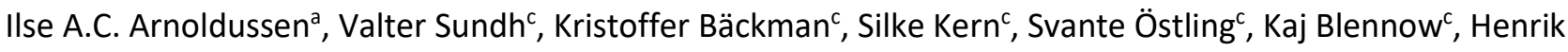
Zetterberg ${ }^{\mathrm{c}}$, Ingmar Skoog ${ }^{\mathrm{c}}$, Amanda J. Kiliaan ${ }^{\mathrm{a}}$ and Deborah R. Gustafson ${ }^{\mathrm{b}, \mathrm{c}, \mathrm{d}}$

${ }^{a}$ Donders Institute for Brain, Cognition and Behaviour, Department of Anatomy, Radboud university medical center, Nijmegen, The Netherlands

${ }^{\mathrm{b}}$ Department of Neurology, State University of New York, Downstate Medical Center, New York, USA

${ }^{\mathrm{C}}$ Neuropsychiatric Epidemiology Unit, Sahlgrenska Academy at University of Gothenburg, Institute for Neuroscience and Physiology, Gothenburg, Sweden

${ }^{\mathrm{d} D e p a r t m e n t}$ of Health and Education, University of Skövde, Sweden

\section{Corresponding author:}

Deborah R. Gustafson

Department of Neurology

State University of New York-Downstate Medical Center

450 Clarkson Avenue, Box 1213 Brooklyn, New York 11203, USA

Phone: +1 7182701581

Email: deborah.gustafson@downstate.edu

\section{Manuscript details}

Supplemental data: no

Title: 15 words, 87 characters

Abstract: 278

Manuscript: 3518

Tables/figures: 1 figure / 3 tables

References: 57

Keywords: body mass index, waist hip ratio, leptin, adiponectin, dementia, elderly

Running title: Adiposity indicators and dementia in elderly 


\section{Abstract}

\section{Background:}

Adiposity measured in mid- or late-life, and estimated using anthropometric measures such as body mass index (BMI) and waist-to-hip ratio (WHR), or metabolic markers such as blood leptin and adiponectin levels, is associated with late-onset dementia risk. However, during later life this association may reverse and agingand dementia-related processes may differentially affect adiposity measures.

\section{Objective:}

We explored associations of concurrent BMI, WHR, and blood leptin and high molecular weight adiponectin levels with dementia occurrence.

\section{Methods:}

924 Swedish community-dwelling elderly without dementia, aged 70 years and older, systematicallysampled by birth day and birth year population-based in the Gothenburg city region of Sweden. The Gothenburg Birth Cohort Studies are designed for evaluating risk and protective factors for dementia. All dementias diagnosed after age 70 for 10 years were identified. Multivariable logistic regression models were used to predict dementia occurrence between 2000-2005, 2005-2010, and 2000-2010 after excluding prevalent baseline (year 2000) dementias. Baseline levels of BMI, WHR, leptin and adiponectin were used. 


\section{Results:}

Within 5 years of baseline, low BMI $\left(<20 \mathrm{~kg} / \mathrm{m}^{2}\right)$ was associated with higher odds of dementia compared to those in the healthy BMI category $\left(\geq 20-24.9 \mathrm{~kg} / \mathrm{m}^{2}\right)$. Compared to the lowest quartile, leptin levels in the second quartile were associated with lower odds of dementia in women $(p<0.05)$.

\section{Conclusion:}

In late-life, anthropometric and metabolic adiposity measures appear to be differentially associated with dementia risk. While BMI and leptin levels are highly positively correlated, our results show that their association with dementia at age $\geq 70$ years, is asynchronous. These data suggest that with aging, the complexity of the adiposity exposure may increase and suggests metabolic dysregulation. Additional studies are needed to better understand this complexity. 


\section{Introduction}

In later life, lower body mass index (BMI), being underweight by definition, and declining BMI (despite one's BMI level at onset of decline), are associated with greater risk of late-onset dementias [1, 2]. In mid- or adult life, higher BMI is prospectively associated with dementia risk [1]. This difference in the mid-life versus latelife BMI-dementia risk association is often referred to as the 'obesity paradox' and evidence of reverse causality [3].

Anthropometric characteristics are sculpted by amount and distribution of adipose tissue. Changes in this important tissue result from lifetime variations in energy balance, sociocultural background, and epigenetic phenomena, and develop secondarily to central pathophysiological changes in preclinical and clinical dementia [4]. Therefore, adiposity indicators like BMI, waist-hip ratio (WHR), and circulating blood levels of adipokines, such as leptin and adiponectin, are potential risk markers for dementia [5-8]. Since adipose tissue is the primary source of both of these adipokines, leptin and adiponectin are good biomarkers of this tissue's metabolic activity.

There is limited and ambiguous published research regarding the link between adipokine levels and sporadic, late-onset dementias $[9,10]$. However, leptin is associated with insulin resistance and brain health,[11, 12] and is the adipose tissue hormone [13] most studied in association with brain structure and function. Leptin has numerous effects on brain development [14], and potentially on brain health in cognition and aging. Peripheral leptin enters the central nervous system and interacts with specific areas of the brain such as the hypothalamus and hippocampus [15]. In addition to crossing the BBB [16], several studies indicate that 
leptin is also produced in the brain, for example in the hypothalamus, cortex and cerebellum [17, 18]. Leptin has been prospectively associated with dementia over 8 years [19], but not over 24 years, from mid- to latelife [20]. Leptin is positively correlated with total and central anthropometric adiposity measures [21, 22].

Adiponectin is a visceral adipose tissue marker and exists as complex multimeric isoforms comprised of high molecular weight (HMW) hexamers and trimers [23]. It is an effective insulin sensitizer, and circulating levels are inversely correlated with insulin resistance, metabolic syndrome, adiposity, type 2 diabetes, and cardiovascular diseases. Adiponectin modulates inflammatory responses, energy expenditure (CNS and periphery), food intake (CNS), and a number of metabolic processes, including glucose regulation and fatty acid catabolism in the periphery. Since blood-brain barrier (BBB) transport mechanisms for adiponectin are unclear, blood levels may not indicate potential interactions between adiponectin and the brain [24].

We investigated the association between dementia occurrence and both anthropometric and adipokine indicators of adiposity - BMI, WHR, and blood leptin and adiponectin levels - in a 10-year prospective population-based study of Swedish adults, aged 70 years and older. Moreover, we examined whether these adiposity markers predict dementia occurrence over the short- and/or long-term. This study will further reveal the complex interplay between surrogate markers of adiposity and dementia onset.

\section{Methods}

\section{Participants}


Participants comprising the Gothenburg Birth Cohort Studies, originate from two epidemiological studies in Gothenburg, Sweden: 1) the Prospective Population Study of Women (PPSW) and 2) the Gerontological and Geriatric Population Studies (H70). Both have been described in detail previously [25-27]. Eligible participants were sampled from the Swedish Population Register based on birth date. PPSW participants were born in 1908, 1914, 1918, 1922 and 1930. H70 participants were born in 1930. Adults living in private households and residential care were included. There were 1725 eligible individuals in 2000-2001, and 1018 agreed to participate (response rate 59.0\%). Among these, 857 (84.2\%) consented to genetic analyses. Due to the nature of PPSW and H70, women $(n=700)$ were $70-92$ years and men $(n=224) 70$ years. Participants included 339 H70 females at age 70, 224 H70 males at age 70, and 361 PPSW females age 70 years and older (Fig. 1). Follow-up examinations were conducted in 2005-06 and 2009-10, and 689 participated in 2005-06 (response rate among survivors, 82.2\%), and 518 in 2009-10 (response rate among survivors, $76.7 \%$ ).

Those who died, or declined participation during follow-up, were traced in records from hospitals and homes for the aged, inpatient and outpatient departments in psychiatric hospitals and clinics, municipal psychiatric outpatient departments in Gothenburg, the hospital-linkage system, and death certificates [28]. All participants (or their closest relatives) gave informed consent, which was conducted in accordance to the provisions of the Helsinki Declaration. The study was approved by the Ethics Committee for Medical Research at the University of Gothenburg.

\section{Dementia assessment}

Dementia diagnoses were made according to the Diagnostic and Statistical Manual of Mental Disorders 3rd Edition Revised (DSM-III-R) [29, 30] at examinations in 2000-2001, 2005-2006 and 2009-2010. This dementia 
diagnosis was made according to components of the Alzheimer's Disease Assessment Scale-Cognitive subscale (ADAS-Cog). A close informant interview was conducted using IQCode [31]. Symptom domains relevant for making a dementia diagnosis include: memory (short-term, long-term), aphasia (language disturbance), apraxia (inability to carry out motor activities despite intact function), agnosia (failure to identify or recognize objects despite intact sensory function), executive function (planning, organizing, abstract thinking) and personality changes (used in DSM-IIIR criteria for dementia, not in DSM-IV or DSM-V). Participants must have evidenced significant impairment in social or occupational functioning representing significant decline from a previous level of functioning. There was also a global rating of symptom status made by the interviewer (psychiatrist or psychiatric nurse) and information from close informants related to dementia symptoms. The Comprehensive Psychiatric Rating Scale (CPRS) [32], an extensive neuropsychiatric inventory, was used to rate psychiatric symptoms and signs at face-to-face examinations. The Mini-Mental Examination (MMSE) was used as an additional evaluation of global cognitive impairment, but is not considered diagnostic by itself. In addition, the Swedish Hospital Discharge Registry provided diagnostic information for individuals discharged from hospitals since 1978. Medical records were collected from hospitals and outpatient departments in Sweden's public health care system. Incident cases of dementia up to December 31, 2010 were also based on information from the Swedish Hospital Discharge Register (ICD10: F00.1, F01.8, F01.9, F03.9, G30.9). Thus, dementia diagnoses were obtained for all study participants, since almost all people in Sweden receive health care from the community and have an equal chance of having a medical record. Dementia was diagnosed by neuropsychiatrists at consensus meetings based on all information sources available, e.g., neuropsychiatric examinations, medical records, and close informant interviews. 


\section{Anthropometric assessments}

Anthropometric measurements were conducted in the morning when participants wore light clothing at each examination[33]. Body weight was recorded to the nearest $0.1 \mathrm{~kg}$, and body height was measured to the nearest $0.5 \mathrm{~cm}$. BMI was calculated as $\mathrm{kg} / \mathrm{m}^{2}$. Waist and hip circumferences were measured to the nearest $0.5 \mathrm{~cm}$. Measures of each were conducted until there was agreement within $0.5 \mathrm{~cm}$.

\section{Blood measures}

Blood samples were collected after a 12 -hour fast, and plasma aliquots stored at $-70^{\circ} \mathrm{C}$. Regarding baseline adipokine measures, control standards and participant samples were tested in duplicate using High Molecular Weight (HMW) adiponectin and leptin ELISA assays (Linco Research, Inc, St. Louis, MO 63304) in the Clinical Chemistry Department at the University of Gothenburg.

Blood lipids including cholesterol, high density lipoprotein (HDL), low density lipoprotein (LDL), and triglycerides, were measured at the certified Sahlgrenska Hospital Laboratory.

DNA was extracted from blood samples according to standard procedures. APOE (gene map locus 19q13.2) genotyping was performed by mini-sequencing as previously described in detail [34]. Genotypes were obtained for the two SNPs (rs7412 and rs429358), which are used to unambiguously define $\varepsilon 2$, $\varepsilon 3$, and $\varepsilon 4$ alleles. 


\section{Lifestyle assessments and medical history}

Level of education (completing six years compulsory education or less $v s$ at least compulsory education);

socioeconomic status (SES, working vs middle/upper class); alcohol consumption and cigarette smoking (ever vs never use); medication use; and medical history were queried at each examination. Diagnoses of myocardial infarction, stroke, cancer, and diabetes were self-reported as well as determined by clinical examinations (ECG and blood samples), case records, hospital discharge registry, national cancer registry, and national stroke registry. Systolic (SBP) and diastolic blood pressures (DBP) were measured while participants were sitting down and at rest for at least 5 minutes. Depressive symptoms were measured using the Montgomery-Åsberg depression rating scale (MADRS) [35].

\section{Statistical analyses}

Means and standard deviations were calculated for all continuous variables, and frequencies and percentages for categorical variables. BMI, WHR, leptin and adiponectin were used in analyses as continuous, and as traditional quartiled categorical variables. We considered baseline adiposity exposures at 2000 and 2005, and percent BMI change from 2000-2005 in association with dementia occurring between 2005 and 2010. Clinically relevant BMI change was categorized as $+/->5 \%$, and $+/->10 \%$. We created combined anthropometric and adipokine categories as potentially better surrogates of adiposity-associated risk $[36,37]$. We cross-tabulated leptin quartiles by the four traditional BMI (underweight, $<20.00 \mathrm{~kg} / \mathrm{m}^{2}$; healthy, $20.00-24.99 \mathrm{~kg} / \mathrm{m}^{2}$; overweight, $25.00-29.99 \mathrm{~kg} / \mathrm{m}^{2}$; and obese $\geq 30.00 \mathrm{~kg} / \mathrm{m}^{2}$ ) categories. In other words, those with a low leptin and low BMI were compared to those with a high leptin and high BMI, versus 
either alone. Similarly, leptin quartiles were cross-tabulated by WHR (central obesity: men $>0.90 \mathrm{~cm}$, women $>0.85)$.

Multivariable logistic regression analyses were used to calculate odds ratios (OR) for developing dementia over different time periods. First, regression models estimated the odds of dementia over ten years (20002010) given adiposity exposures measured at baseline in 2000 . Second, we estimated the association between baseline adiposity indicators measured in 2000 among those without dementia and subsequent dementia occurring during two five year periods, 2000-2005 and 2005-2010. To reiterate, prevalent dementia cases at baseline were excluded from all models. In models predicting dementia by adipokines, we adjusted for BMI if the correlation between adipokine and BMI did not exceed $r \geq 0.70$.

Selection of covariates originated from a pool of potentially biologically relevant variables: age; sex; education; socioeconomic status (SES); smoking; alcohol intake; depressive symptoms; diabetes; cancer; heart attack; stroke/transient ischemic attack; hypertension; blood triglyceride, cholesterol, HDL, LDL, and glucose levels; DBP; SBP; and APOEع4 genotype. All potential covariates were included in age-adjusted logistic regression models predicting dementia over the entire follow-up period. Age, sex, SES, smoking status (ever/never), diabetes (yes/no), alcohol intake (ever/never), depressive symptoms (MADRS score > 12), and presence of at least one APOE 44 allele were significant at $p \leq 0.05$ and included in multivariable models. Two-tailed tests were used with a significance level of $p \leq 0.05$. SPSS, version 20.0 (IBM Corporation, Armonk, New York, USA), was used to perform data analyses. 


\section{Results}

Overall, 924 adults (224 men and 700 women) without dementia, participated in the baseline (year 2000) examination. PPSW and H70 were representative of the population base with regard to sex; marital status; income; community rent allowance for those who could not afford housing; rate of inpatient and outpatient care in psychiatric hospitals, clinics, and municipal outpatient departments; and rates of registration with the Temperance Board (national registry for alcohol abuse). Over ten years, 134 participants developed dementia.

The average age of the participants at baseline $(n=924)$ was 74.0 years, and when stratified by sex, the average age of men was 70.0 years and for women, 75.3 years (Table 1 ). Compared to men, women were more likely to be underweight and had higher plasma levels of leptin and adiponectin. Approximately $25 \%$ of the study population had at least one APOE\&4 allele (27.7\% in men and $24.4 \%$ in women).

Multivariable logistic regression models were used to examine the relationship between continuous baseline adiposity indicators and subsequent dementias. No associations were found between BMI, WHR, leptin or adiponectin and dementia occurrence in the entire sample over the ten year follow up (Table 2; data not shown for adipokines).

To better understand the temporality of association between adiposity markers and dementia, we divided the ten year follow-up period into two five year dementia occurrence intervals - 2000-2005 and 2005-2010 (Table 2), as has been done previously [38]. When analyzed continuously, a higher baseline BMI lowered the 
odds of dementia within five years. However, using traditional BMI categories, participants with an 'underweight' BMI $\left(<20 \mathrm{~kg} / \mathrm{m}^{2}\right)$ had higher odds of developing dementia compared to participants with a 'healthy' BMI (reference category BMI 20.00-24.9 kg/m²) (Table 2). This finding among underweight may have driven the protective association observed when BMI was modelled as a continuous variable. This association was driven by female participants (Table 2).

In women, we also found an association between leptin levels and odds of dementia within the first five years of follow up (2000-2005, Table 3). No associations were observed in men. Baseline leptin levels in the second quartile (18.66 - $30.52 \mathrm{ng} / \mathrm{mL}$ ) were associated with lower odds of developing dementia compared to leptin levels in the first quartile ( $\leq 18.65 \mathrm{ng} / \mathrm{mL}$, reference). No associations were found between serum levels of HMW adiponectin and dementia occurrence.

Considering only dementias occurring during 2005-2010, there were no associations with baseline BMI, WHR, leptin or adiponectin (Table 2). In addition, BMI change from 2000-2005 was not associated with dementias occurring from 2005-2010 (data not shown). Combinations of anthropometric BMI or WHR risk categories by leptin quartiles did not shed any additional light on these associations (data not shown).

\section{Discussion}

In an elderly Swedish sample of women and men, we observed that a low BMI $(<20 \mathrm{~kg} / \mathrm{m} 2)$ was associated with over a 5-fold higher odds of developing dementia within five years in women, aged 70 years and older. Given published literature on mid-life obesity and later onset dementia, this may be evidence of an obesity paradox and/or reverse causality. However, without mid-life measures, we cannot be sure. In addition, the 
odds of developing dementia were $70 \%$ lower in women aged 70 years and older who had intermediate serum leptin levels based on analysis of leptin quartiles. Thus, despite a robust correlation of $r=0.71$ between BMI and leptin in this sample, there is a suggestion that these adiposity indicators were differentially associated with development of dementia within 5 years of measurement in elderly women. Other studies in middle-aged and elderly women have suggested contradictory associations between anthropometric versus leptin levels and cognition or dementia $[10,39,40]$.

Our analyses support a first-ever published report from the original Gothenburg Birth Cohort Study (H70) among those born 1901/02 [38]. Similar to the 2003 report, there was no association between higher BMI and dementia observed during the first 10 years of follow-up. In contrast to the 2003 report, the current analysis includes primarily those born 1930 . Thus, with further follow-up, we will be able to observe a 30 year cohort comparison of the BMI-dementia association. In addition, we also chose to focus on all dementias, due to controversies and changes in the field regarding diagnoses of dementia subtypes without the use of neuroimaging or cerebrospinal fluid biomarkers [41].

Our study has many advantages. First, the population sample is part of a long-standing series of rich longitudinal birth cohort studies in Sweden beginning in 1968 (PPSW) and 1971 (the first H70 cohort) [25, 26], with consistent measures over time among unique birth cohorts. Second, there is long follow-up of a large sample of rigorously studied elderly, age 70 years and older, and adjustment for multiple potential confounders. Third, we measured blood levels of adipokines reflecting the metabolic activity of adipose tissue. Finally, we used the study design to our advantage, to estimate temporal (shorter versus longer term) 
associations of adiposity indicators with dementia. Given the important role of temporality in understanding risk and protective factor-dementia associations, we see this as a definite strength of these studies.

As with any study design, there are limitations. First, while data from the Gothenburg Birth Cohort Studies have been published using this merged sample examined with identical methods by the same research group at the same time $[42,43]$, the study is unbalanced regarding sex and age. All men were aged 70 years at baseline, whereas women were aged 70 years and older. Thus, our observations regarding sex differences should be interpreted cautiously. Second, a small number of male participants reduced the power for analyzing associations in men given that dementia onset was monitored during a period of relatively low risk, notably the $8^{\text {th }}$ decade of life [38]. Third, leptin and adiponectin measures were only measured at baseline, thus repeated measures and change in these important hormones over time cannot be considered. Fourth, other nutritional influencers of BMI and WHR, including estimates of energy intake and expenditure, are unavailable. Fifth, our leptin findings are rather conservative. While leptin has strong mechanistic actions in the brain, the use of this marker in the periphery as a reflection of the fat-brain axis remains unclear, especially at a life stage when there are ageing-related body composition changes. In addition, replication of our observations regarding leptin is essential. Finally, some may deem four and five year examination intervals to characterize date of dementia onset as unacceptable. However, given the insidious and often slowly progressive course of dementia onset and a population-based sample, we deem it highly acceptable for these types of analyses. Calculating odds ratios (OR), given this nuance, closely approximates the risk. We have shown this in a previous publication on adiposity measures and dementia [38]. 
While we found that the odds of developing dementia are higher in elderly women with low BMI within five years, this is not a new finding. The association between BMI and dementia appears to change over the life course. Some studies show that adults with a high midlife BMI or central obesity have a higher risk of latelife dementia [1]. Others have reported that weight loss or BMI decline is associated with dementia risk in elderly $[44,45]$. Our data did not suggest associations of baseline BMI and dementias occurring between 2000-2010 nor dementias occurring between 2005 and 2010. Nor was BMI change from 2000-2005 related to dementias occurring between 2005-2010. This suggests temporal issues regarding the BMI-dementia association in this sample, however we cannot evaluate this historically since we do not have measures of BMI prior to 70 years. Thus, a lower BMI may be a preclinical marker for underlying dementia development within five years of a clinical diagnosis in women aged 70 years and older. These results should be interpreted with caution due to a small number of women in the lowest BMI category. The association of lower baseline BMI with dementia may result from a lengthier period of weight loss accompanying prodromal dementia prior to age 70 years, supporting BMI as a possible preclinical marker of dementia.

That low BMI may be a preclinical marker for dementia, is suggested by neuropathophysiological changes accompanying dementia. These changes can induce changes in body weight and adipose storage. For example, brain areas that control weight (i.e. mesial temporal cortex) are affected during the preclinical dementia phase; and adipose tissue loss may result from preclinical apathy, reduced olfactory function, difficulty with eating (e.g., aphasia), inadequate nutrition or prescribed medicines targeting dementia related symptoms e.g. depression or cognitive impairments [46]. 
Furthermore, we found that the odds of developing dementia in elderly women were lower among those with intermediate blood leptin levels. Postmenopausal women may have a greater risk of developing dementia than men, perhaps due to changes in leptin and brain function due to a fall in endogenous estrogen levels following menopause [47]. Estrogen and leptin have neuroprotective effects on cognition by regulating neurogenesis, hippocampal synaptic plasticity, and axonal growth [11]. However, the roles of adipokines are diverse, and often enigmatic. The adiposity-dementia association, remains to be elucidated, as this is by no means clear.

As higher levels of adiposity, commonly measured as anthropometric overweight and obesity, are associated with higher risk for cardiovascular disease (CVD) [48, 49], and CVD is a risk factor for dementia [50], we explored CVD variables as potential covariates. None were significantly associated with dementia in ageadjusted models. This null observation associating dementia with CVD risk in late-life concurs with other published reports [51]. In addition, adiponectin, known to be associated with CVD, was not associated with dementia.

The underlying neurodegenerative and vascular pathologies observed in dementia, and subsequent impairment of key fat-brain and gut-brain feedback loops [52], may be at the root of conflicting observations; and seemingly intertwined adiposity factors may be differentially associated with dementia when measured within five years. Our findings are supported by studies reporting that higher levels of leptin are prospectively associated with lower odds of dementia or mild-cognitive impairment in elderly [10, 53 , 54]. Metabolic dysregulation may accompany or promote late-life alternations in leptin levels and dementias [55]. Atrophy of the posterior hypothalamus affects appetite and feeding behavior via disintegration of 
network connections and effects on hormone synthesis $[55,56]$. In addition, higher levels of leptin are observed to be neuroprotective [57].

\section{Conclusion}

Two highly correlated adiposity variables measured in late life do not associate similarly with late-onset dementia in women. Our analyses show a higher odds of dementia with a low BMI, and a lower odds of dementia with intermediate leptin levels when dementia occurs within 5 years of the adiposity measurement among women aged 70 years and older. Lower BMI and higher leptin may potentially characterize aspects of metabolic dysregulation associated with presence versus absence of prodromal dementia. However, both associations suggest a similar adiposity phenomenon, whether cast as lower BMI being risky or higher leptin levels being protective.

\section{Acknowledgements}

This research was supported by a fellowship grant of Alzheimer Nederland (2014) for data analysis and manuscript preparation; and the State University of New York - Downstate Medical Center institutional research support for technical and scientific oversight and guidance. Funding of data collection, entry, compilation and maintenance; all laboratory measures; and dementia diagnoses were funded over time by: Swedish council (11267, 2005-8460, 2007-7462, 2012-5041, 2015-02830, 2013-8717); Swedish Research Council for Health, Working Life and Welfare (no 2001-2646, 2003-0234, 2004-0150, 2006-0020, 2008-1229, 2012-1138, 2004-0145, 2006-0596, 2008-1111, 2010-0870, 2013-1202, AGECAP 2013-2300, 2013-2496, Epilife 2006-1506); Konung Gustaf V:s och Drottning Victorias Frimurarestiftelse, Hjärnfonden, Sahlgrenska University Hospital (ALF); The Alzheimer's Association Zenith Award (ZEN-01-3151); The Alzheimer's 
Association Stephanie B. Overstreet Scholars (IIRG-00-2159); Eivind och Elsa K:son Sylvans stiftelse, Stiftelsen Söderström-Königska Sjukhemmet, Stiftelsen för Gamla Tjänarinnor and Handlanden Hjalmar Svenssons Forskningsfond. No author has been paid to write this manuscript. The corresponding author (DRG) had full access to all data and final decision to submit the manuscript in consultation with IS, the Principal Investigator of the Gothenburg Birth Cohort Studies.

Conflicts of Interest. All authors have no conflicts of interest. 


\section{References}

[1] Emmerzaal TL, Kiliaan AJ, Gustafson DR (2015) 2003-2013: a decade of body mass index, Alzheimer's disease, and dementia. J Alzheimers Dis 43, 739-755.

[2] Besser LM, Gill DP, Monsell SE, Brenowitz W, Meranus D, Kukull W, Gustafson DR (2014) Body mass index, weight change, and clinical progression in mild cognitive impairment and Alzheimer's disease. Alzheimer disease and associated disorders 28, 36.

[3] Fitzpatrick AL, Kuller LH, Lopez OL, Diehr P, O'Meara ES, Longstreth WT, Jr., Luchsinger JA (2009) Midlife and late-life obesity and the risk of dementia: cardiovascular health study. Arch Neuro/ 66, 336-342.

[4] Johnson DK, Wilkins CH, Morris JC (2006) Accelerated weight loss may precede diagnosis in Alzheimer disease. Arch Neurol 63, 1312-1317.

[5] Kiliaan AJ, Arnoldussen IA, Gustafson DR (2014) Adipokines: a link between obesity and dementia? Lancet Neurol 13, 913-923.

[6] Johnston JM, Hu WT, Fardo DW, Greco SJ, Perry G, Montine TJ, Trojanowski JQ, Shaw LM, Ashford JW, Tezapsidis N, Alzheimer's Disease Neuroimaging I (2014) Low plasma leptin in cognitively impaired ADNI subjects: gender differences and diagnostic and therapeutic potential. Curr Alzheimer Res 11, 165-174.

[7] Littlejohns TJ, Kos K, Henley WE, Cherubini A, Ferrucci L, Lang IA, Langa KM, Melzer D, Llewellyn DJ (2015) Serum leptin and risk of cognitive decline in elderly italians. J Alzheimers Dis 44, 1231-1239.

[8] van Himbergen TM, Beiser AS, Ai M, Seshadri S, Otokozawa S, Au R, Thongtang N, Wolf PA, Schaefer EJ (2012) Biomarkers for insulin resistance and inflammation and the risk for all-cause dementia and alzheimer disease: results from the Framingham Heart Study. Arch Neurol 69, 594-600.

[9] Oania R, McEvoy LK (2015) Plasma leptin levels are not predictive of dementia in patients with mild cognitive impairment. Age Ageing 44, 53-58.

[10] Zeki Al Hazzouri A, Stone KL, Haan MN, Yaffe K (2013) Leptin, mild cognitive impairment, and dementia among elderly women. J Gerontol A Biol Sci Med Sci 68, 175-180. 
[11] Arnoldussen IA, Kiliaan AJ, Gustafson DR (2014) Obesity and dementia: adipokines interact with the brain. Eur Neuropsychopharmacol 24, 1982-1999.

[12] Kiliaan AJ, Arnoldussen IA, Gustafson DR (2014) Adipokines: a link between obesity and dementia? Lancet Neurol 13, 913-923.

[13] Lieb W, Beiser AS, Vasan RS, Tan ZS, Au R, Harris TB, Roubenoff R, Auerbach S, DeCarli C, Wolf PA, Seshadri S (2009) Association of plasma leptin levels with incident Alzheimer's disease and MRI measures of brain aging. JAMA 302, 2565-2572.

[14] Harvey J, Shanley L, O'Malley D, Irving AJ (2005) Leptin: a potential cognitive enhancer? Biochem Soc Trans 33, 1029-1032.

[15] Peiser C, McGregor GP, Lang RE (2000) Binding and internalization of leptin by porcine choroid plexus cells in culture. Neurosci Lett 283, 209-212.

[16] Schulz C, Paulus K, Lehnert H (2010) Adipocyte-brain: crosstalk. Results Probl Cell Differ 52, 189-201.

[17] Morash B, Li A, Murphy PR, Wilkinson M, Ur E (1999) Leptin gene expression in the brain and pituitary gland. Endocrinology 140, 5995-5998.

[18] Wiesner G, Vaz M, Collier G, Seals D, Kaye D, Jennings G, Lambert G, Wilkinson D, Esler M (1999) Leptin is released from the human brain: influence of adiposity and gender. J Clin Endocrinol Metab 84, $2270-2274$.

[19] Lieb W, Beiser AS, Vasan RS, Tan ZS, Au R, Harris TB, Roubenoff R, Auerbach S, DeCarli C, Wolf PA, Seshadri S (2009) Association of plasma leptin levels with incident Alzheimer disease and MRI measures of brain aging. JAMA 302, 2565-2572.

[20] Gustafson D, Lissner L, Bengtsson C, Bjorkelund C, Skoog I (2004) A 24-year follow-up of body mass index and cerebral atrophy. Neurology 63, 1876-1881.

[21] Friedman J, Halaas L (1998) Leptin and the regulation of body weight in mammals. Nature 22, 763770. 
[22] Lissner L, Karlsson C, Lindroos AK, Sjostrom L, Carlsson B, Carlsson L, Bengtsson C (1999) Birth weight, adulthood BMI, and subsequent weight gain in relation to leptin levels in Swedish women. Obes Res 7, 150-154.

[23] Sinha MK, Songer T, Xiao Q, Sloan JH, Wang J, Ji S, Alborn WE, Davis RA, Swarbrick MM, Stanhope KL, Wolfe BM, Havel PJ, Schraw T, Konrad RJ, Scherer PE, Mistry JS (2007) Analytical validation and biological evaluation of a high molecular-weight adiponectin ELISA. Clin Chem 53, 2144-2151.

[24] Drolet ea (2008) Fat depot-specific impact of visceral obesity on adipocyte adiponectin release in women. Obesity (Silver Spring) 17, 424-430.

[25] Steen B, Djurfeldt H (1993) The gerontological and geriatric population studies in Gothenburg, Sweden. Z Gerontol 26, 163-169.

[26] Bengtsson C, Blohme G, Hallberg L, Hällström T, Isaksson B, Korsan-Bengtsen K, Rybo G, Tibblin E, Tibblin G, Westerberg H (1973) The study of women in Gothenburg 1968-79. A population study. General design, purpose and sampling results. Acta Med Scand 193, 311-318.

[27] Bengtsson C, Ahlquist M, Andersson K, Björkelund C, Lissner L, Söderström M (1997) The Prospective Population Study of Women in Gothenburg, Sweden, 1968-69 to 1992-93. A 24-year follow-up study with special reference to participation, representativeness, and mortality. Scand J Primary Health Care 15, 214-219.

[28] Skoog I, Nilsson L, Palmertz B, Andreasson LA, Svanborg A (1993) A population-based study of dementia in 85-year-olds. N Engl J Med 328, 153-158.

[29] APA (1987) Diagnostic and statistical manual of mental disorders. 3rd ed. rev.:DSM-III-R, American Psychiatric Association, Washington, D.C.

[30] Skoog I, Lernfelt B, Landahl S, Palmertz B, Andreasson LA, Nilsson L, Persson G, Oden A, Svanborg A (1996) 15-year longitudinal study of blood pressure and dementia. Lancet 347, 1141-1145.

[31] Jorm AF, Korten AE, Henderson AS (1987) The prevalence of dementia: a quantitative integration of the literature. Acta Psychiatr Scand 76, 465-479. 
[32] Åsberg M, Perris C, Schalling D, Sedvall G (1978) The CPRS - development and applications of a psychiatric rating scale. Acta Psychiatr Scand suppl 271.

[33] Bengtsson C, Hallberg L, Noppa H, Tibblin E (1979) Anthropometric data in middle-aged women. The population study of women in Goteborg 1968-1969. Acta Morphol Neerl Scand 17, 133-143.

[34] Blennow K, Ricksten A, Prince JA, Brookes AJ, Emahazion T, Wasslavik C, N. B, Andreasen N, Batsman S, Marcusson J, Nagga K, Wallin A, Regland B, Olofsson H, Hesse C, Davidsson P, Minthon L, Jansson A, Palmqvist L, Rymo L (2000) No association between the alpha2-macroglobulin (A2M) deletion and Alzheimer's disease, and no change in A2M mRNA, protein, or protein expression. J Neural Transm 107, 1065-1079.

[35] Montgomery SA, Asberg M (1979) A new depression scale designed to be sensitive to change. Br J Psychiatry 134, 382-389.

[36] Kerwin DR, Gaussoin SA, Chlebowski RT, Kuller LH, Vitolins M, Coker LH, Kotchen JM, Nicklas BJ, Wassertheil-Smoller S, Hoffmann RG, Espeland MA, Women's Health Initiative Memory S (2011) Interaction between body mass index and central adiposity and risk of incident cognitive impairment and dementia: results from the Women's Health Initiative Memory Study. J Am Geriatr Soc 59, 107112.

[37] National Heart LaBI, Classification of Overweight and Obesity by BMI, Waist Circumference, and Associated Disease Risks,National Institutes of Health, https://www.nhlbi.nih.gov/health/educational/lose wt/BMI/bmi dis.htm, Accessed 27-09-2017.

[38] Gustafson D, Rothenberg E, Blennow K, Steen B, Skoog I (2003) An 18-year follow-up of overweight and risk of Alzheimer disease. Arch Intern Med 163, 1524-1528.

[39] Gustafson DR, Mielke MM, Keating SA, Holman S, Minkoff H, Crystal HA (2015) Leptin, adiponectin and cognition in middle-aged HIV-infected and uninfected women. The Brooklyn Women's Interagency HIV Study J Gerontol Geriatric Res 4. 
[40] Gustafson DR, Mielke MM, Tien PC, Valcour V, Cohen M, Anastos K, Liu C, Pearce L, Golub ET, Minkoff H, Crystal HA (2013) Anthropometric measures and cognition in middle-aged HIV-infected and uninfected women. The Women's Interagency HIV Study. J Neurovirol 19, 574-585.

[41] ADRD summit 2016 committee (2016) Alzheimer's disease-related dementias.

[42] Wancata J, Borjesson-Hanson A, Ostling S, Sjogren K, Skoog I (2007) Diagnostic criteria influence dementia prevalence. Am J Geriatr Psychiatry 15, 1034-1045.

[43] Zettergren A, Kern S, Gustafson D, Gudmundsson P, Sigstrom R, Ostling S, Eriksson E, Zetterberg H, Blennow K, Skoog I (2017) The ACE Gene Is Associated with Late-Life Major Depression and Age at Dementia Onset in a Population-Based Cohort. Am J Geriatr Psychiatry 25, 170-177.

[44] Atti AR, Palmer K, Volpato S, Winblad B, De Ronchi D, Fratiglioni L (2008) Late-life body mass index and dementia incidence: nine-year follow-up data from the Kungsholmen Project. J Am Geriatr Soc 56, 111-116.

[45] Hughes TF, Borenstein AR, Schofield E, Wu Y, Larson EB (2009) Association between late-life body mass index and dementia: The Kame Project. Neurology 72, 1741-1746.

[46] Franx BAA, Arnoldussen IAC, Kiliaan AJ, Gustafson DR (2017) Weight Loss in Patients with Dementia: Considering the Potential Impact of Pharmacotherapy. Drugs Aging 34, 425-436.

[47] Wu YT, Fratiglioni L, Matthews FE, Lobo A, Breteler MM, Skoog I, Brayne C (2016) Dementia in western Europe: epidemiological evidence and implications for policy making. Lancet Neurol 15, 116124.

[48] Stillman CM, Weinstein AM, Marsland AL, Gianaros PJ, Erickson KI (2017) Body-Brain Connections: The Effects of Obesity and Behavioral Interventions on Neurocognitive Aging. Front Aging Neurosci 9, 115.

[49] van Emmerik NM, Renders CM, van de Veer M, van Buuren S, van der Baan-Slootweg OH, Kist-van Holthe JE, Hirasing RA (2012) High cardiovascular risk in severely obese young children and adolescents. Arch Dis Child. 
[50] Kivipelto M, Ngandu T, Fratiglioni L, Viitanen M, Kareholt I, Winblad B, Helkala EL, Tuomilehto J, Soininen H, Nissinen A (2005) Obesity and vascular risk factors at midlife and the risk of dementia and Alzheimer disease. Arch Neurol 62, 1556-1560.

[51] Alonso A, Jacobs DR, Jr., Menotti A, Nissinen A, Dontas A, Kafatos A, Kromhout D (2009) Cardiovascular risk factors and dementia mortality: 40 years of follow-up in the Seven Countries Study. J Neurol Sci 280, 79-83.

[52] Morley JE (2010) Nutrition and the Brain. Clinics in Geriatric Medicine 26, 89-98.

[53] Holden KF, Lindquist K, Tylavsky FA, Rosano C, Harris TB, Yaffe K, Health ABCs (2009) Serum leptin level and cognition in the elderly: Findings from the Health ABC Study. Neurobiol Aging 30, 14831489.

[54] Zeki Al Hazzouri A, Haan MN, Whitmer RA, Yaffe K, Neuhaus J (2012) Central obesity, leptin and cognitive decline: the Sacramento Area Latino Study on Aging. Dement Geriatr Cogn Disord 33, 400409.

[55] Finger EC (2017) Increased heart rate and energy expenditure in frontotemporal dementia. Brain $140,10-12$.

[56] Ahmed RM, Latheef S, Bartley L, Irish M, Halliday GM, Kiernan MC, Hodges JR, Piguet O (2015) Eating behavior in frontotemporal dementia: Peripheral hormones vs hypothalamic pathology. Neurology 85, 1310-1317.

[57] Magalhaes CA, Carvalho MG, Sousa LP, Caramelli P, Gomes KB (2015) Leptin in Alzheimer's disease. Clin Chim Acta 450, 162-168. 
Figure 1. Flowchart of participant characteristics and number at baseline and in follow-up examinations

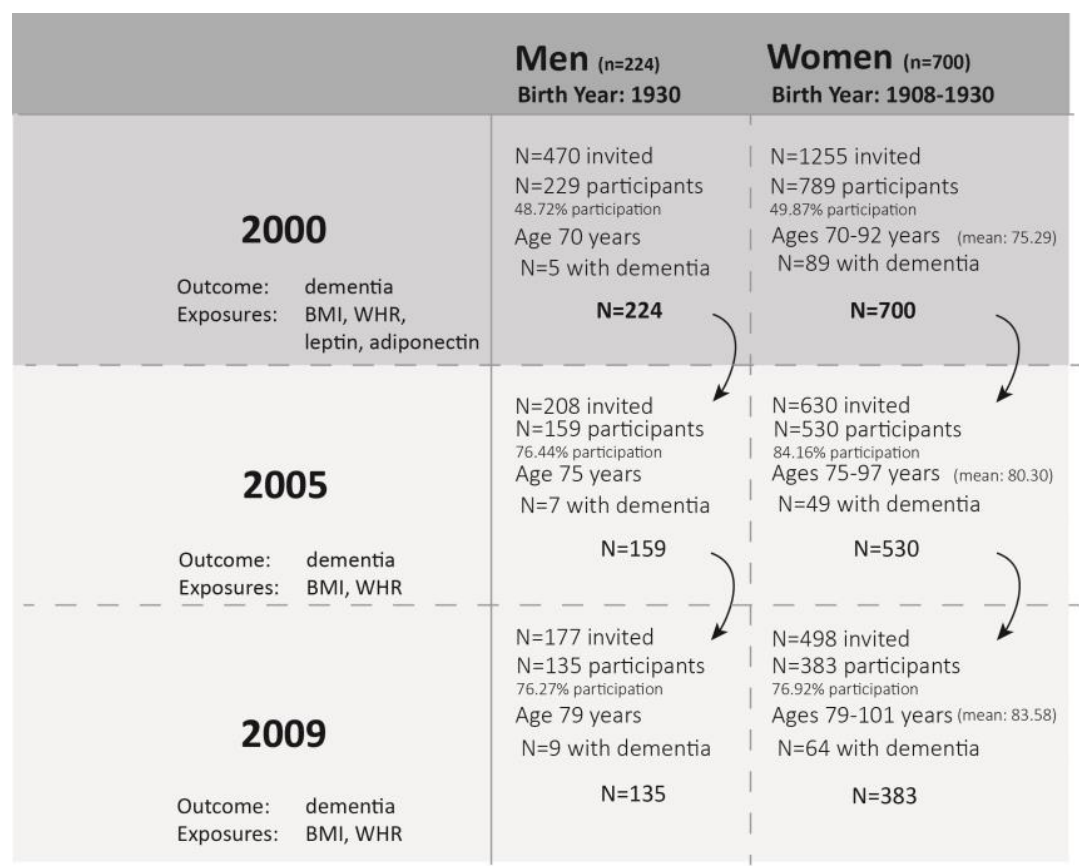


Table 1. Baseline characteristics of participants without dementia in the Gothenburg Birth Cohort Studies

\begin{tabular}{|c|c|c|c|}
\hline Variable & All $(n=924)$ & Men $(n=224)$ & Women $(n=700)$ \\
\hline Age, years, mean \pm SD & $74.0 \pm 5.3$ & $70.0 \pm 0.0$ & $75.3 \pm 5.5$ \\
\hline Education <8 years, $\mathrm{N}(\%)$ & $544(58.9)$ & $125(55.8)$ & 419 (59.9) \\
\hline \multicolumn{4}{|l|}{ Socioeconomic status (SES) } \\
\hline working class, N (\%) & $351(38.0)$ & 57 (25.4) & $294(42.0)$ \\
\hline middle or upper class, $\mathrm{N}(\%)$ & $300(32.5)$ & $100(44.6)$ & $200(28.6)$ \\
\hline Waist-hip ratio (WHR), mean \pm SD & $0.87 \pm 0.083$ & $0.95 \pm 0.06$ & $0.84 \pm 0.07$ \\
\hline Low WHR: men $\leq 0.90$, women $\leq 0.85, \mathrm{~N}(\%)$ & $375(40.6)$ & $33(14.7)$ & $342(48.9)$ \\
\hline High WHR: men >0.90, women $>0.85, \mathrm{~N}(\%)$ & $509(55.1)$ & $186(83.0)$ & $323(46.1)$ \\
\hline $\mathrm{BMI}, \mathrm{kg} / \mathrm{m}^{2}$, mean $\pm \mathrm{SD}$ & $26.7 \pm 4.2$ & $29.9 \pm 3.9$ & $26.6 \pm 4.3$ \\
\hline$\leq 20.00, N(\%)$ & $28(3.0)$ & $4(1.8)$ & $24(3.4)$ \\
\hline $20.01-24.99, \mathrm{~N}(\%)$ & $290(31.4)$ & $66(29.5)$ & $224(32.0)$ \\
\hline $25.00-29.99, \mathrm{~N}(\%)$ & $375(40.6)$ & $108(48.2)$ & $267(38.1)$ \\
\hline$\geq 30.00, \mathrm{~N}(\%)$ & $180(19.5)$ & $45(20.1)$ & $135(19.3)$ \\
\hline Leptin $(\mathrm{ng} / \mathrm{mL})$, mean $\pm \mathrm{SD}$ & $31.6 \pm 24.0$ & $15.07 \pm 10.5$ & $37.28 \pm 24.7$ \\
\hline $\mathrm{Q} 1(\mathrm{ng} / \mathrm{mL})$ & $\leq 13.36$ & $\leq 8.06$ & $\leq 18.65$ \\
\hline Q2 (ng/mL) & $13.37-25.24$ & $8.07-12.04$ & $18.66-30.52$ \\
\hline Q3 (ng/mL) & $25.25-44.00$ & $12.05-21.07$ & $30.53-50.83$ \\
\hline $\mathrm{Q} 4$ (ng/mL) & $>44.00$ & $>21.07$ & $>50.83$ \\
\hline Adiponectin $(\mathrm{ng} / \mathrm{mL})$, mean $\pm \mathrm{SD}$ & $6.10 \pm 4.54$ & $3.52 \pm 2.34$ & $6.97 \pm 4.77$ \\
\hline Q1 (ng/L) & $\leq 3.11$ & $\leq 1.97$ & $\leq 3.76$ \\
\hline Q2 (ng/L) & $3.12-4.89$ & $1.98-3.01$ & $3.77-5.71$ \\
\hline Q3 (ng/L) & $4.90-7.84$ & $3.02-4.57$ & $5.72-8.90$ \\
\hline Q4 (ng/L) & $>7.84$ & $>4.57$ & $>8.90$ \\
\hline \multicolumn{4}{|l|}{ Alcohol consumption } \\
\hline g per week, mean \pm SD & $37.5 \pm 66.9$ & $72.2 \pm 101.9$ & $25.63 \pm 44.4$ \\
\hline Smoking, ever, N (\%) & $353(38.2)$ & $151(67.4)$ & $202(28.9)$ \\
\hline \multicolumn{4}{|l|}{ Serum levels (mmol/L) } \\
\hline Triglycerides, mean \pm SD & $1.4 \pm 0.7$ & $1.41 \pm 0.6$ & $1.46 \pm 0.8$ \\
\hline Cholesterol, mean \pm SD & $5.9 \pm 1.1$ & $5.5 \pm 0.9$ & $6.1 \pm 1.0$ \\
\hline High density lipoprotein (HDL), mean \pm SD & $1.6 \pm 0.4$ & $1.3 \pm 0.4$ & $1.7 \pm 0.4$ \\
\hline Low density lipoprotein (LDL), mean \pm SD & $3.7 \pm 0.9$ & $3.6 \pm 0.9$ & $3.8 \pm 0.9$ \\
\hline Systolic blood pressure, mean \pm SD & $157.7 \pm 22.5$ & $155.1 \pm 23.1$ & $158.2 \pm 22.3$ \\
\hline Diabetes mellitus, N (\%) & $111(12.0)$ & $41(18.2)$ & $70(9.9)$ \\
\hline Depression, $* \mathrm{~N}(\%)$ & $99(10.7)$ & $15(6.7)$ & $84(12.0)$ \\
\hline Presence of any Apoe $\varepsilon 4$ allele, $+\mathrm{N}(\%)$ & $233(25.2)$ & $62(27.7)$ & $171(24.4)$ \\
\hline
\end{tabular}

*Clinically relevant depressive symptom burden, MADRS score $>12$. †APOE $\varepsilon 4$ allele: apolipoprotein epsilon 4 allele. 
Table 2. Odds of developing dementia from 2000-2010, 2000-2005, and 2005-2010 by baseline BMI and WHR among participants without dementia. The Gothenburg Birth Cohort Studies.

\begin{tabular}{|c|c|c|c|c|c|c|c|c|c|}
\hline & \multicolumn{3}{|l|}{ 2000-2010 } & \multicolumn{3}{|l|}{ 2000-2005 } & \multicolumn{3}{|l|}{ 2005-2010 } \\
\hline & $\begin{array}{l}\text { Total } \\
\text { OR }(95 \% \mathrm{Cl})\end{array}$ & $\begin{array}{l}\text { Men } \\
\text { OR }(95 \% \mathrm{Cl})\end{array}$ & $\begin{array}{l}\text { Women } \\
\text { OR }(95 \% \mathrm{Cl})\end{array}$ & $\begin{array}{l}\text { Total } \\
\text { OR }(95 \% \mathrm{Cl})\end{array}$ & $\begin{array}{l}\text { Men } \\
\text { OR }(95 \% \mathrm{Cl})\end{array}$ & $\begin{array}{l}\text { Women } \\
\text { OR ( } 95 \% \mathrm{Cl})\end{array}$ & $\begin{array}{l}\text { Total } \\
\text { OR }(95 \% \mathrm{Cl})\end{array}$ & $\begin{array}{l}\text { Men } \\
\text { OR }(95 \% \mathrm{Cl})\end{array}$ & $\begin{array}{l}\text { Women } \\
\text { OR }(95 \% \mathrm{Cl})\end{array}$ \\
\hline \multicolumn{10}{|c|}{ Baseline BMI (kg/m²) } \\
\hline Continuous & $0.94(0.86-1.02)$ & $0.99(0.85-1.10)$ & $0.92(0.83-1.01)$ & $0.88(0.79-0.97)^{*}$ & $0.89(0.67-1.18)$ & $0.87(0.78-0.97)^{* *}$ & $0.99(0.89-1.11)$ & $0.99(0.83-1.21)$ & $0.98(0.86-1.12)$ \\
\hline$<20.0$ & $2.94(0.73-11.88)$ & $\mathrm{NE}+$ & $4.59(0.95-22.22)$ & $4.21(1.03-17.21)^{*}$ & $\mathrm{NE}$ & 5.34 (1.19-23.87) & $1.12(0.13-9.41)$ & $\mathrm{NE}$ & $1.32(0.14-11.45)$ \\
\hline $20.00-24.99+$ & 1.0 & 1.0 & 1.0 & 1.0 & 1.0 & 1.0 & 1.0 & 1.0 & 1.0 \\
\hline $25.00-29.99$ & $0.79(0.39-1.56)$ & $1.34(0.34-5.24)$ & $0.67(0.29-1.50)$ & $0.13(0.25-1.19)$ & $0.39(0.04-3.37)$ & $0.54(0.24-1.27)$ & $0.69(0.28-1,74)$ & $1.91(0.33-11.26)$ & $0.45(0.14-1.43)$ \\
\hline$\geq 30.00$ & $0.93(0.39-2.22)$ & $0.80(0.13-5.10)$ & $0.92(0.34-2.51)$ & $0.25(0.19-1.54)$ & $0.51(0.04-6.94)$ & $0.51(0.16-1.66)$ & $1.21(0.41-3.57)$ & $0.76(0.06-9.29)$ & $1.29(0.38-4.40)$ \\
\hline \multicolumn{10}{|c|}{ Baseline WHR $(\mathrm{cm})$} \\
\hline Continuous & $1.07(0.69-1.65)$ & $2.95(0.92-9.42)$ & $0.87(0.54-1.39)$ & $0.95(0.59-1.51)$ & $0.80(0.17-3.80)$ & $0.96(0.59-1.57)$ & $1.20(0.65-2.24)$ & $4.75(1.03-21.78)$ & $0.81(0.42-1.55)$ \\
\hline Low WHR' & 1.0 & 1.0 & 1.0 & 1.0 & 1.0 & 1.0 & 1.0 & 1.0 & 1.0 \\
\hline High WHR & $0.80(0.42-1.52)$ & $3.13(0.37-26.52)$ & $0.62(0.30-1.28)$ & $0.63(0.32-1.27)$ & $0.54(0.05-5.45)$ & $0.63(0.31-1.32)$ & $1.11(0.47-2.65)$ & $\mathrm{NE}$ & $0.77(0.29-2.06)$ \\
\hline
\end{tabular}

Multivariable models included the following covariates: in 2000-2010, age, sex, socio-economic status (SES), ApoEع4 allele, and smoking; in 2000-2005, age, sex, depressive symptoms and SES; in 2005-2010, age, sex and smoking. †Reference category. Multivariable models were assessed for the complete cohort (total), and subsequent for both men and women in the cohort. Low WHR: men $\leq 0.90 \mathrm{~cm}$, women $\leq 0.85$; High WHR: men $>0.90 \mathrm{~cm}$, women $>0.85$.

Number of incident dementias in 2000-2010, N=134 (men N=18 and women N=116); in 2000-2005, N=68 (men N=8 and women N=60); and in 2005-2010, $\mathrm{N}=66$ (men $\mathrm{N}=10$ and women $\mathrm{N}=56)$. ${ }^{*} \mathrm{NE}$ : not estimable due to small number. ${ }^{*} \mathrm{P}<0.05 ;{ }^{* *} \mathrm{P}<0.001$. 
Table 3. Odds of developing dementia from 2000-2010, 2000-2005, and 2005-2010 by baseline leptin and adiponectin among participants without dementia. The Gothenburg Birth Cohort Studies.

\begin{tabular}{|c|c|c|c|c|c|c|c|c|c|c|c|}
\hline & & & \multicolumn{3}{|l|}{$2000-2010$} & \multicolumn{3}{|l|}{ 2000-2005 } & \multicolumn{3}{|l|}{ 2005-2010 } \\
\hline & & & Total & Men & Women & Total & Men & Women & Total & Men & Women \\
\hline & & & OR $(95 \% \mathrm{Cl})$ & OR $(95 \% \mathrm{Cl})$ & OR $(95 \% \mathrm{Cl})$ & OR (95\% Cl) & OR $(95 \% \mathrm{Cl})$ & OR (95\% Cl) & OR $(95 \% \mathrm{Cl})$ & OR $(95 \% \mathrm{Cl})$ & OR $(95 \% \mathrm{Cl})$ \\
\hline \multicolumn{12}{|c|}{ Baseline leptin (ng/mL) } \\
\hline Contir & uous & & $0.55(0.23-1.30)$ & $0.96(0.18-5.16)$ & $0.48(0.17-1.31)$ & $0.33(0.11-0.99)^{*}$ & $0.42(0.04-4.33)$ & $0.36(0.1-1.0)^{*}$ & $0.82(0.23-2.89)$ & $1.76(0.17-18.70)$ & $0.56(0.12-2.56)$ \\
\hline \multicolumn{12}{|c|}{ Quartiles } \\
\hline & Men & Women & & & & & & & & & \\
\hline Q1† & $\leq 8.06$ & $\leq 18.64$ & 1.0 & 1.0 & 1.0 & 1.0 & 1.0 & 1.0 & 1.0 & 1.0 & 1.0 \\
\hline Q2 & $8.07-12.04$ & $18.65-30.52$ & $1.15(0.51-2.63)$ & $0.30(0.06-1.55)$ & $1.87(0.69-5.10)$ & $2.62(0.73-9.42)$ & $1.91(0.21-23.52)$ & $0.32(0.10-0.97)^{*}$ & $0.65(0.22-1.89)$ & $0.35(0.05-2.65)$ & $0.92(0.25-3.36)$ \\
\hline Q3 & $12.05-21.07$ & $30.53-50.83$ & $1.17(0.51-2.71)$ & $0.56(0.11-2.67)$ & $0.63(0.59-4.52)$ & $3.47(1.0-12.02)$ & $1.65(0.12-22.41)$ & $0.82(0.32-2.04)$ & $0.37(0.10-1.31)$ & $0.29(0.03-3.13)$ & $0.35(0.07-1.73)$ \\
\hline Q4 & $>21.07$ & $>50.83$ & $0.33(0.07-1.59)$ & $0.44(0.08-2.57)$ & $0.79(0.26-2.47)$ & $0.66(0.11-3.83)$ & $\mathrm{NE}$ & $0.45(0.13-1.13)$ & $0.390 .08-1.99)$ & $0.69(0.10-4.58)$ & $0.62(0.25-2.18)$ \\
\hline \multicolumn{12}{|c|}{ Baseline adiponectin (ng/mL) } \\
\hline Contir & luous & & $1.14(0.38-3.40)$ & $0.49(0.07-3.45)$ & $1.63(0.42-6.33)$ & $1.63(0.32-8.31)$ & $1.18(0.06-25.13)$ & $1.77(0.26-12.22)$ & $0.89(0.22-3.54)$ & $0.30(0.03-3.29)$ & $1.53(0.25-9.30)$ \\
\hline \multicolumn{12}{|c|}{ Quartiles } \\
\hline & Men & Women & & & & & & & & & \\
\hline Q1+ & $\leq 1.97$ & $\leq 3.76$ & 1.0 & 1.0 & 1.0 & 1.0 & 1.0 & 1.0 & 1.0 & 1.0 & 1.0 \\
\hline Q2 & $1.98-3.01$ & $3.78-5.71$ & $0.39(0.15-1.51)$ & $0.19(0.02-1.74)$ & $0.49(0.16-1.48)$ & $0.43(0.10-1.82)$ & $1.22(0.07-22.11)$ & $0.29(0.05-1.65)$ & $0.36(0.10-1.24)$ & NE & $0.67(0.16-2.73)$ \\
\hline Q3 & $3.02-4.57$ & $5.73-8.90$ & $0.74(0.31-1.07)$ & $0.89(0.21-3.83)$ & $0.62(0.22-1.77)$ & $1.06(0.33-3.43)$ & $2.52(0.19-34.24)$ & $0.81(0.21-3.13)$ & $0.53(0.18-1.61)$ & $0.53(0.09-2.91)$ & $0.44(0.09-2.03)$ \\
\hline Q4 & $>4.57$ & $>8.90$ & $0.93(0.42-2.08)$ & $0.38(0.06-2.27)$ & $1.19(0.47-3.03)$ & $1.19(0.38-3.77)$ & $1.19(0.07-21.63)$ & $1.08(0.31-3.76)$ & $0.79(0.28-2.21)$ & $0.22(0.02-2.23)$ & $1.29(0.36-4.56)$ \\
\hline & Mul & variable $\mathrm{m}$ & els include in 2 & 00-2010, age, & x, social econc & nic status (SES) & poEs4 allele, an & smoking; in 20 & -2005, age, sex & depressive sym & oms \\
\hline & and & $E S$; in $2005-$ & 10, age, sex a & smoking. $+R$ & erence catego & Multivariable & odels were ass & ed for the com & te cohort (to & ), and subsequ & for \\
\hline & men & and women. & adiponectin & alyses BMI w & included as c & ariate. NE: not & timable due to & all number. $\mathrm{N}$ & ber of incider & dementias in: 2 & \\
\hline & 2010 & $\mathrm{~V}=134(\mathrm{~m}$ & $\mathrm{V}=18$ and $w 0$ & $\mathrm{n} \mathrm{N}=116), 20$ & $-2005 N=68$ & $\mathrm{n} \mathrm{N}=8$ and $\mathrm{w}$ & $\mathrm{n} \mathrm{N}=60)$ & & & & \\
\hline
\end{tabular}

